\title{
AMBIENTE PSICOLOGICO EN LAS ORGANIZACIONES
}

Por: Damarcy Cortés Baracaldo Psicóloga practicante

IMA

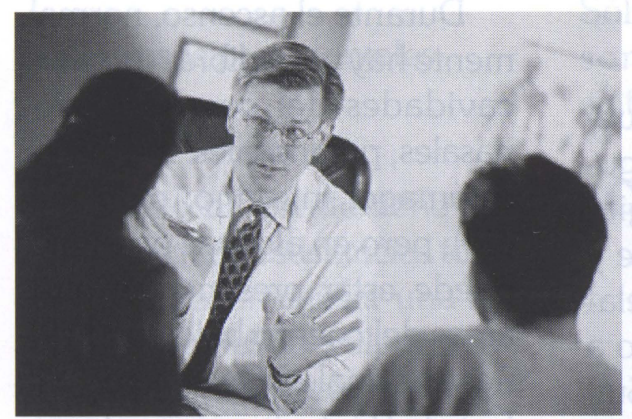

bientales del personal para su mayor rendimiento.

Los resultados de esta investigaciones tanto sistemáticas como informales, han arrojado una relación directa y proporcional entre la motivación del personal y el cumplimiento de los objetivos de la organi-

El talento humano en las organizaciones se ha convertido en las últimas décadas en un recurso que se administra de acuerdo al estilo de liderazgo del jefe, lo que implica una marcada relación hacia la tarea, hacia las relaciones con el personal o una combinación de estas dos, que desencadenan en un ambiente psicológico exclusivo en cada organización.

De esta manera, la interacción de elementos tanto personales como ambientales que conforman ese ambiente psicológico o clima organizacional, influyen directamente en el desempeño de los empleados y por ésto se ha convertido en el tema predilecto de investigación de psicólogos y otros especialistas, enmarcados en la premisa conductista fundamental "el individuo reacciona de acuerdo al ambiente", $y$ por esto se requieren estrategias que provean de un equilibro entre las necesidades personales y am-

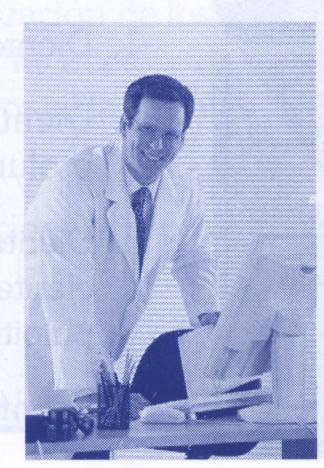
zación, que conllevan a que al aumentar significativamente esta variables, se optimice el clima organizacional.

A su vez, las organizaciones asumen el rol de propender por un aumento en el nivel de motivación de sus empleados, como factor básico del clima, al considerar que las organizaciones con alta motivación tienden a ser exitosas y a cumplir con sus objetivos, ya que el personal recibe un ambiente agradable, tiene ganas de trabajar, colabora con sus compañeros y está en constante disposición de cambio, de tal manera que el no propender por esta motivación, teniendo en cuenta la escala de necesidades en la que se encuentre cada grupo personal, traerá como consecuencia insatisfacción colectiva, ausentismo laboral, bajo sentido de pertenencia y desconexión psicológica con el trabajo.

En tiempos de crisis económica y reajus- te de personal en las empresas, se requiere hacer un minucioso análisis del comportamiento organizacional que contribuya a fortalecer el clima o ambiente psicológico, aumentando la motivación y partiendo de la premisa que el individuo tiene la necesidad de autorrealizarse, poseer autonomía y mejorar progresivamente su calidad de vida; por esto, los directivos de la organización están llamados a modificar su estilo de liderazgo directivo, por uno más participativo en el que se fomente la cultura de tratar a las personas como expertos responsables de su cargo, que disfrutan de su entorno laboral y que contribuyan al éxito de la organización de manera significativa, ya que sus necesidades básicas están totalmente cubiertas y se sienten satisfechos laboralmente.

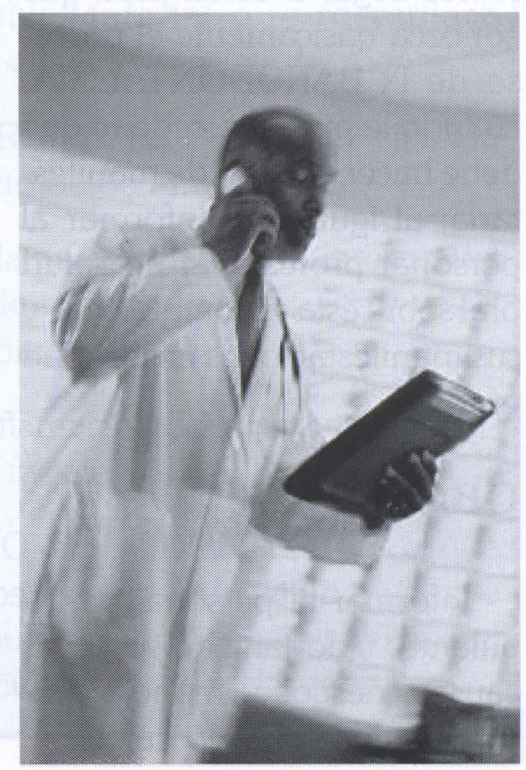

